\title{
Natural Dyeing of Cotton Fabric by Extruded Pelargonidin of Red Onion Skin and Finished it Naturally with Aloe Vera
}

\author{
Ashish Debnath*, Ismat Zerin, Md Mahmudul Hasan, NiloySarker, Kayum Ahmed and Faysal Mahmud \\ Department of Textile Engineering, National Institute of Textile Engineering and Research, Nayarhat, Savar, Dhaka, Bangladesh
}

Submission: August 20, 2018; Published: September 14, 2018

*Corresponding author: Ashish Debnath, National Institute of Textile Engineering and Research, Nayarhat, Savar, Dhaka, Bangladesh, Tel: 8801836061551; Email: ashishdebnathtex011@gmail.com

\begin{abstract}
According to the opinion of the Ecologist, the Textile industry is regarded as the most polluting sectors. Almost every single day, various textile industries mostly Dyeing factories are ejaculating different toxic chemicals, dyes and other agents which are very much harmful to our nature and environment. As a result, the demand for natural dyes has increased abundantly. Natural dyes are environment friendly. In this project, we used onion outer skins as a potential source of natural plant dyes. These dyes, which are known as pelargonidin were applied on cotton fabric by the exhaust method. For proper fixation, drying and curing is carried out in Mini Thermosol Machine. The dyed sample was evaluated for color fastness to washing, light, rubbing and perspiration. The fastness properties were satisfactory. Natural plants that are used as antibacterial finishing agent have a greater market value. As a source of antibacterial finishing agent, Aloe Vera leaf gel applied on Cotton fabric, which has been using as a medium to support the growth of microorganisms, is used. The antibacterial finish has been imparted to cotton by the pad-dry-cure method. The Aloe Vera treated samples have been tested as per Parallel Streak method and found very high inhibition against bacteria.
\end{abstract}

Keywords: Red Onion Skin; Aloe Vera; Cotton fabric; Antibacterial; Color Fastness

\section{Introduction}

Eco-friendly and biodegradable materials caught significant attention all around the globe in recent times[1]. The idea of applying natural dyes on textile materials not only supports the cause but also bears a huge potential in terms of revolutionizing the field of textile. Increased awareness regarding the environmental issues has vastly encouraged the idea as natural dyes are bio-degradable and better compatible with environment[2]. Natural dyes can be extracted from roots, leaves, flowers fruits which are basically parts of plants[3]. It can also be obtained from animals[3]. The dye molecules are pigment molecules having aromatic rings structure coupled with a side chain impart color to the material by resonating and also by virtue of the co-relation between the chemical structure and color plus chromogen- chromophore with auxochrome[4]. Onion skin is an easily available material to extract a particular natural dye from known as pelargonidin. There are four hydroxyl groups in a molecule which act as the auxochrome groups in order for the pelargonidin to impart good dyeing properties with a view to dyeing natural fibers[2].

Textile materials as a substrate can easily be vulnerable to bacterial growth and microbial growth given the right conditions as in moisture, nutrients, temperature etc. [5] Hence, anti-bacterial finishing has been largely focused here as health and hygiene is always the top priority and concern[6] For antimicrobial finishing, an agent is due which is capable of eliminating the growth of micro-organisms as in bacteria, fungi, algae, yeast etc[6]. Natural fibers are comparatively more exposed to the bacterial attack than synthetic fibers because of their porous and hydrophilic nature[5]. And it's because of their tendency to absorb water and oxygen with nutrients, micro-organisms are favored with environment that can easily support their survival and growth. On top of that, human body acts as a source of warmth, humidity and nutrients which supports the bacteria's cause even more[6]. The proliferation of micro-organisms can be responsible for the malodors, stains and wreckage of the mechanical properties of the component fibers which may lead to the product being less suitable for the purposed use. This fact has raised the necessity for the textile product which would be bio-functional capable of performing anti-microbial activities. There are herbal compounds, extractable from plants which are not only well recognized for such anti-microbial properties but also available in abundance around us in nature. Along with being cost efficient, these products are non-irritant and nontoxic to human skin[6]. 
The prime goal of this project is to use Aloe Vera leaves in order for its anti-microbial properties to perform an ecofriendly antibacterial finishing on textile products. The aim of this research is to reduce the uses of synthetic dyes and make people aware about the necessity of using natural dyes and natural finishing agents for the betterment of environment. This research helps people to utilize the natural sources and plants like Aloe Vera and Red onion skins and apply these sources on textile and dyeing industries all over the world.Onion Skin dyes which also called pelargonidin (3,5,7,4-tetrahydroxyanthocyanidin)[3], that can dye the Cotton, protein fibers effectively. The presence of four hydroxy groups (Auxochrome groups) pelargonidin is the main reason of better dyeing abilities for dyeing of natural fibers [2]. Figure 1 Chemical Structure of Pelargonidin[3]Onion outer skin which is contained Flavonoid, Tannin, Cardiac glycoside, Anthraquinone etc[7]. The lower leaves of the plant is the main source for obtaining the Aloe vera inner gel. The gel can be extracted by slicing the leaf open. The gel is clear, odorless, and tasteless and free from the yellow parts of leaf skin[8]. Aloe Vera gel which is contained Vitamins,Sugars,Minerals,Hormones,Anthraquinone (alloin,emodin) etc $[9,10]$.<smiles>Oc1ccc(-c2[o+]c3cc(O)cc(O)c3cc2O)cc1</smiles>

Figure 1: Chemical Structure of Pelargonidin[3].

\section{Materials and Methods}

\section{Materials}

Source of Dye: Red Onion outer skin which was collected from Nayarhat, Savar, Dhaka.

Natural Antibacterial Source: Fresh Aloe Vera plants were collected from Panchdona, Narsingdi.

Nutrient Agar Source: Nutrient agar was brought from Mitali Chemicals House, Gulisthan, Dhaka.

Bacteria Source: Bacteria was collected from Laboratory.

\section{Instruments:}
a) Beaker
b) Thermometer
c) Glass rod
d) Burner
e) Electric Balance
f) Mini Themosol Machine

\section{Methodology}

Extraction of the Natural Dye: In aqueous extraction process, the coloring matter was withdrawn from the skins. Required amount of liquor was taken and boil at $(65-80)^{\circ} \mathrm{Cfor}$ 50-70 min. When the mixture was cooled down, the dye extracts were filtered accurately in each process of extraction. The temperature, concentration and time combination were taken as the optimum condition of extraction of dye because they yield maximum absorption[2].

\section{Dyeing of Cotton Fabric with Extruded Pelargonidin Dye}

Dyeing Procedure: The dyeing of scoured and bleached cotton fabric was conducted in exhaust method. Fabric was weighted in Electric balance. Then required amount of liquor and other necessary auxiliaries was calculated. A beaker was taken and required amount of liqour taken into beaker. Then the fabric was immersed into the dye solution. Dyeing was carried out at $75^{\circ} \mathrm{C}$ for $60 \mathrm{~min}$ in acidic medium. After dyeing, hot wash was done with hot water at $50^{\circ} \mathrm{C}$ for $10 \mathrm{~min}$.Then cold wash was done at $30^{\circ} \mathrm{C}$ at 10 minute.

Drying and Fixation: After dyeing, drying and curing was done in mini thermosol machine. Drying is done at $150^{\circ} \mathrm{C}$ to dry the fabric. Then curing is done at $200^{\circ} \mathrm{C}$ to fix the dye into the fabric. The machine speed was $10 \mathrm{rpm}$.

Extraction of Aloe Vera Gel: Aloe vera leaf is collected from the plant. To remove the dirt from the aloe vera leaf, washing is necessary. With the use of our hands solid gel converts into liquid gel by massaging. Aloe vera gel is extracted from inner parts of the leaf by using spoon[10].

Aloe Vera Gel Solution: $60 \mathrm{gm}$ of aloe vera gel is mixed with $40 \mathrm{~mL}$ of water (Aloe Vera:Water $=60: 40$ ) and boiled for 10 $\min$ at $50^{\circ} \mathrm{C}$ to produce aloe vera gel solution. The mixture was cooled down in each process of extraction. The temperature, concentration and time combination were taken as the optimum condition of extraction of dye because they yield maximum absorption.

\section{Microbial Finishing of Cotton Fabric with Aloe Vera Gel by} Pad-Dry-Cure Method

a) Padding: Microbial finishing of cotton fabric with aloe vera gel was done in mini thermosol machine. Aleovera gel solution taken in liqour trough. Then the fabric was passed into liqour trough. Aloe vera gel is coated in fabric which was done by padder. The pressure of padder is 5 bar.

b) Drying: Drying is done at $150^{\circ} \mathrm{C}$ to dry the fabric.

c) Curing: Then curing is done at $200^{\circ} \mathrm{C}$ to fix the aloe vera gel into the fabric. The machine speed was $10 \mathrm{rpm}$.

\section{Method of Color Fastness Test}

a) Color Fastness to Wash: For Color fastness to Wash, BSEN ISO 105 C06 method was followed. 
b) Color Fastness to Rubbing: For Color Fastness to Rubbing,BSEN ISO 105*12 method was followed.

c) Color Fastness to Perspiration: For Color Fastness to Perspiration,BSEN ISO 105 E04 method was followed.

d) Color Fastness to Light: For Color Fastness to Light,BSEN ISO B02 method was followed.

\section{Antibacterial Test for Finished Sample}

For Antibacterial Test,parallel streak method AATCC-147 was used to prove the antibacterial activity of Aloe Vera gel applied on the cotton fabric by assessment the inhibition zone of bacterial culture.

\section{Result and Discussion}

\section{Dyed Sample}

By applying the same process and procedure as well as recipe we got the following results:(Figure 2).

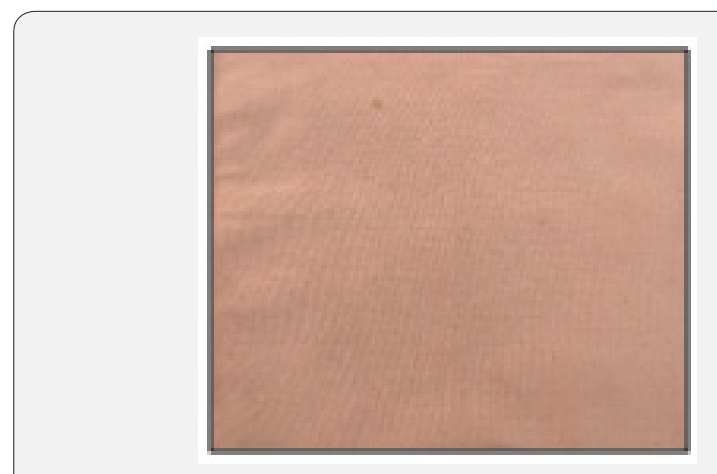

Figure 2: Pelargonidin dyed Sample.

a. Fastness Result OfDyed Sample

b. Color Fastness to Wash: The Rating of color fastness to washing of the dyed sample was evaluated and presented in the below Table 1.

Tables 1: The results of color fastness to washing sample is moderate to good.

\begin{tabular}{|c|c|c|c|c|c|c|c|}
\hline Color Fastness to Wash & Change in Color & Acetate & Cotton & Nylon & Polyester & Acrylic & Wool \\
\hline Rating & 3 & $3-4$ & 3 & $3-4$ & $3-4$ & $3-4$ & 3 \\
\hline
\end{tabular}

Table 2: The results of color fastness to dry rubbing sample is good to Excellent and the results of color fastness to Wet rubbing sample is good.

\begin{tabular}{|c|c|c|}
\hline Color Fastness to Rubbing & Dry Rubbing & Wet Rubbing \\
\hline Rating & $4-5$ & 4 \\
\hline
\end{tabular}

c. Color Fastness to Rubbing: The Rating of color fastness to rubbing of the dyed sample was evaluated and presented in the below Table 2 . d. ColorFastness to Perspiration: The Rating of color fastness to Perspiration of the dyed sample was evaluated and presented in the below Table 3.

Table 3: The Rating of color fastness to Perspiration of the dyed sample was evaluated and presented in the Table.

\begin{tabular}{|c|c|c|c|c|c|c|c|}
\hline Color Fastness to Perspiration & Change in Color & Acetate & Cotton & Nylon & Polyester & Acrylic & Wool \\
\hline Rating for Alkali & 4 & 4 & 4 & $4-5$ & $4-5$ & $4-5$ & $4-5$ \\
\hline Rating for Acid & 4 & $4-5$ & 4 & $3-4$ & $4-5$ & 4 & $4-5$ \\
\hline
\end{tabular}

e. Color Fastness to Light: The Rating of color fastness to Light of the dyed sample were evaluated and presented in the below Table 4 .

Table 4: The results of color fastness to Light of sample is moderate to good.

\begin{tabular}{|c|c|}
\hline Color Fastness to Light & \\
\hline Rating & $3-4$ \\
\hline
\end{tabular}

f. Finished Sample: By applying the same process and procedure as well as recipe we got the following results: (Figure 3).

\section{Color Fastness Result of Finished Fabric}

a) Color Fastness to Wash: The Rating of color fastness to washing of the dyed sample was evaluated and presented in the below Table 5 .

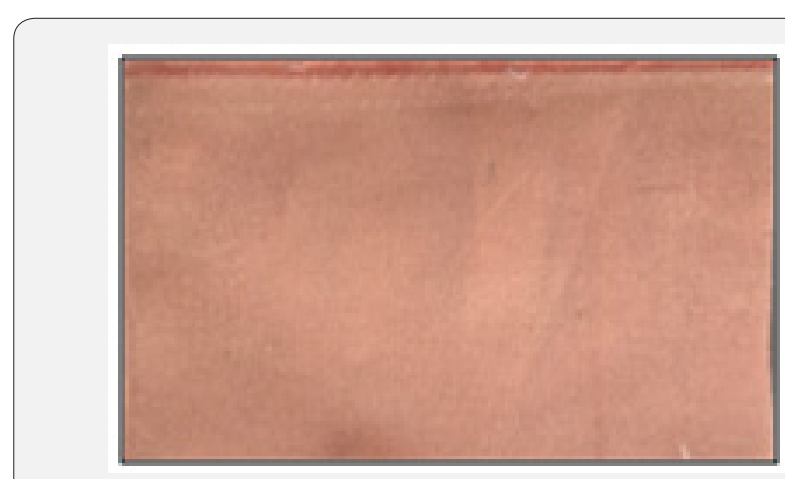

Figure 3: Aloe Vera finished sample.

b) Color Fastness to Rubbing: The Rating of color fastness to rubbing of the dyed sample was evaluated and presented in the below Table 6 . 
Table 5: The results of color fastness to washing sample is good.

\begin{tabular}{|c|c|c|c|c|c|c|c|}
\hline Color Fastness to Wash & Change in Color & Acetate & Cotton & Nylon & Polyester & Acrylic & Wool \\
\hline Rating & 4 & 4 & $4-5$ & $4-5$ & $4-5$ & 4 & 4 \\
\hline
\end{tabular}

Table 6:The results of color fastness to dry rubbing sample is good to Excellent and the results of color fastness to Wet rubbing sample is good.

\begin{tabular}{|c|c|c|}
\hline $\begin{array}{c}\text { Color Fastness to } \\
\text { Rubbing }\end{array}$ & Dry Rubbing & Wet Rubbing \\
\hline Rating & $4-5$ & 4 \\
\hline
\end{tabular}

c) Color Fastness to Perspiration: The Rating of color fastness to Perspiration of the dyed sample was evaluated and presented in the below Table 7 .

d) ColorFastness to Light: The Rating of color fastness to Light of the dyed sample was evaluated and presented in the below Table 8 .

Table 7: The Rating of color fastness to Perspiration of the dyed sample was evaluated and presented in the table.

\begin{tabular}{|c|c|c|c|c|c|c|c|}
\hline Color Fastness to Perspiration & Change in Color & Acetate & Cotton & Nylon & Polyester & Acrylic & Wool \\
\hline Rating for Alkali & 4 & 4 & 4 & $4-5$ & $4-5$ & $4-5$ & $4-5$ \\
\hline Rating for Acid & 4 & $4-5$ & 4 & $3-4$ & $4-5$ & 4 & $4-5$ \\
\hline
\end{tabular}

Table 8: The results of color fastness to Light sample is good.

\begin{tabular}{|c|c|}
\hline Color Fastness to Light & \\
\hline Rating & 4 \\
\hline
\end{tabular}

e) Antibacterial Test Result: Pad-dry samples are treated with aloe vera gel to check the antibacterial activity. The figures shown that, the antibacterial activity of Aloe Vera exhibits against Staphylococcus aureus and E. coil to reasonable extent when aloe vera advents the fabric samples; it bleeds from the samples and shows inhibition against the bacteria. Bacteria colony are absent in the contact area under the sample. A clear zone of inhibition was observed when the fabric samples are tested by parallel streak method to evaluate the antibacterial activity of Aloe Vera treated cotton fabric(Figure 4).

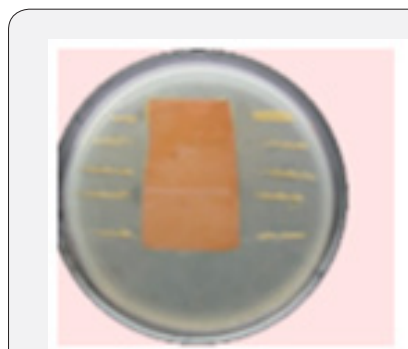

(a)

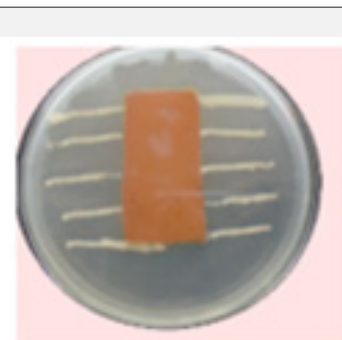

(b)
Figure 4: Aloe Vera treated fabric agains Staphylococcus aureus(a) and Aloe Vera treatedfabric against Escherichia coli(b).

\section{Conclusion}

The environment surrounding us is being polluted daily for using excessive chemicals and other harmful ingredients. Therefore, a global awareness is raised for limiting the use of these ingredients and favoring the use of natural resources. In present research work, it was found that cotton could be dyed with dry Red onion outer skin. The concentration of dye, temperature, time are the parameter which is to be optimized for more effective results. The color fastness test of washing, light, perspiration, rubbing to the samples are shows good fastness property. The onion outer skin can be used as a potential natural source of dyes for the cotton dyeing which was demonstrated by this study. This study gave the chance to change the fashion hues on cotton fabric. Though the gathering of the ingredients is relatively expensive, but the dyes extracted from this type of waste materials can be an attractive alternative. The Aloe Vera leaf gel created a good effect of antibacterial and softness on the cotton fabric. From this work, we came to conclusion that aloe vera extract has the best antibacterial properties which could be achieved by pad dry cure method with the high concentration of aloe vera extract while coated samples with extract could not give such zone of inhibition. It proves that the bacterial inhibition occurred due to the slow release of active substances from the surface of the fabric. From our lab result Aloe Vera gel treated dyed fabric has very high resistance against bacterial habitation.

\section{Acknowledgment}

The authorselicit heartfelt gratefulness to Md. Zahid Hasan (Lecturer,Dept. of Textile Engineering,BGMEA University of Fashion \& Technology) and Rony Miah (Lecturer,Dept. of Textile Engineering,National Institute of Textile Engineering and Research)due to their expert guidance and encouragement in this Research.

\section{References}

1. SSJSMRRS Mona Verma1 (2017) Ecofriendly Dyeing of Cotton Fabric after Biopolymer Treatment by using Outer Skin of Onion. International Journal of Pure \& Applied Bioscience 5(1): 552-557.

2. MG Uddin (2014) Effects of Different Mordants on Silk Fabric Dyed with Onion Outer Skin Extracts. Journal of Textiles.

3. YMM Abdu Zubairu(2015) Effects of Selected Mordants on the Application of Natural Dye from Onion Skin (Allium cepa). Scientific \& Academic Publishing 5(2): 26-32.

4. A SinghDyeing of Wool with Onion Skin. Textile Learner. 
5. Ibrahim W, Sarwar Z, Abid S, Munir U, Azeem A (2017) Aloe Vera Leaf Gel Extract for Antibacterial and Softness Properties of Cotton. Journal of Textile Science \& Engineering.

6. S Hooda, K Khambra, N Yadav, VK Sikka (2013)effect of laundering on herbal finish of cotton.International Journal of Textile and Fashion Technology (IJTFT) 3(4): 35-42.

7. SOEU AB, MDE Sunday,EwaocheItodo (2014) Phytochemical Properties and Staining Ability of Red Onion (Allium cepa)Extract on Histological Sections. Journal of Cytology \& Histology.
8. B Oliver Grundmann (2012) Aloe Vera Gel Research Review. Natural Medicine Journal4(9)

9. RVa DGS Amar Surjushe (2008) Aloe Vera: A Short Review. Indian Journal of Dermatology 53(4): 163-167.

10.K KumarAntimicrobial Finishing Of Cotton Fabric With Aloe Barbadensis. Textile Learner.

\section{Your next submission with Juniper Publishers will reach you the below assets}

- Quality Editorial service

- Swift Peer Review

- Reprints availability

- E-prints Service

- Manuscript Podcast for convenient understanding

- Global attainment for your research

- Manuscript accessibility in different formats ( Pdf, E-pub, Full Text, Audio)

- Unceasing customer service

Track the below URL for one-step submission https://juniperpublishers.com/online-submission.php 